\title{
Formation of Micropillars on Titanium Alloy of Ti6Al4V by R-MEDM Process
}

\author{
Rakesh V. Chaudhari ${ }^{\mathrm{a}}$, Ashish Saxena ${ }^{\mathrm{b}}$, Harit Raval ${ }^{\mathrm{c}}$, and Asim Tewari ${ }^{\mathrm{d}}$
}

\begin{abstract}
The use of titanium is vital in the aerospace sector because of its high strength to weight ratio and excellent fracture resistance. Ti6Al4V is widely used titanium alloy in the aerospace sector. High aspect ratio arrayed micro-structures are required in a broad range of applications such as electrodes for micro-batteries, printing heads, injection nozzles, nano-material delivery systems, biomedical implants and electrical contacts. Reverse micro electro discharge machining (R-MEDM) process enables to manufacture arrayed structures on a variety of workpiece materials independent of their mechanical properties. The R-MEDM differs from micro-electrical discharge machining process in which arrayed projections are developed with the help of pre-machined micro-holes. The main objective of this paper is to study formation of micropillars by R-MEDM process on single crystal Ti6Al4V material. A coarse grain of titanium alloy (Ti6Al4V) was developed by heat treatment at 1050oC for $4 \mathrm{hr}$ followed by air cooling. The effect of key process parameters, voltage, capacitance and threshold of spark circuit on R-MEDM process is reported. It is found that process parameters of voltage $105 \mathrm{~V}$, capacitance of $0.1 \mu \mathrm{m}$ and threshold of $50 \%$ exhibited successful micropillars. The micropillars were polished using polishing slurry of alumina powder and titanium alloy etchant.
\end{abstract}

Keywords - Ti6Al4V, Micro-machining, Micropillars, Reverse micro-EDM process, Grain Growth

\section{INTRODUCTION}

Titanium alloys have found a variety of applications in several industrial areas, especially in the automobile, biomedical, ship building and aerospace sectors. But, the largest consumer of titanium alloys is aerospace industry because of its high strength to weight ratio, high resistance to corrosion, high temperature stability and excellent fracture resistance [1]. Also, the density of titanium alloys is 4.5 $\mathrm{gm} / \mathrm{cc}$, which is $40 \%$ less than that of steel. The most commonly used titanium alloy in aerospace sector is Ti6Al4V which was introduced in the year 1954. It can be used at reasonably high temperatures, has sufficiently high strength to handle excessive stresses and it is one of the stabilized variants among all titanium alloys [2].

Micro-pin arrays of diameters of 35-150 $\mu \mathrm{m}$ and aspect ratios of 10-100 are useful in a wide variety of applications in the field of micro-engineering like fuel/metal injectors, sensors in biomedical devices, MEMS device elements, etc.

\footnotetext{
${ }^{\text {a} P a n d i t ~ D e e n d a y a l ~ P e t r o l e u m ~ U n i v e r s i t y / M e c h a n i c a l ~ d e p a r t m e n t, ~}$ Gandhinagar, Gujarat, India

${ }^{\mathrm{b}}$ Indian Institute of Technology Bombay/Metallurgical Engineering and Materials Science Department, Mumbai, India

${ }^{\mathrm{c}}$ Sardar Vallabhbhai National Institute of Technology, Surat/Mechanical Department, Surat, India

${ }^{\mathrm{d}}$ Indian Institute of Technology, Bombay/Mechanical Department, Mumbai, India
}

All these applications require high aspect-ratio micropillars on metallic components [3,4].For economical manufacturing of such micro-pin arrays, a process known as reverse microelectrical discharge machining (R-MEDM) has come out to be the most promising technology in the recent years than LIGA (German acronym for lithography, electroplating and moulding) and wire-electrical discharge machining (wire$\mathrm{EDM}$ ). The R-MEDM is based on principle of material erosion with the help of controlled sparks. R-MEDM uses a thin plate (cathode) with micro-holes pre-machined by suitable micro-machining process. A larger diameter rod (anode) serves as a workpiece and is mounted over these micro-holes fed through at a controlled feed. Wherever a material to material contact of anode and cathode is present, the anode surface gets eroded. The only material that will be left on the anode surface is the one having the interface with the micro-holes on the cathode plate. This results in the replica of pattern of micro-holes on the anode surface from the cathode surface.

Past research studies have been focused on investigating the manufacturing capability of the R-MEDM process. Kim et al.[5] analyzed the effect of voltage and capacitance while fabricating micro-pins of diameter $30 \mu \mathrm{m}$ and length $1.5 \mathrm{~mm}$ on tungsten carbide (WC) using normal R-EDM process. The process was found to be stable at $100 \mathrm{~V}$ and $650 \mathrm{pF}$ capacitance levels due to reduction in short bridge conditions. The bounds put on the machining rates by the pulse discharge circuits, LIGA-fabricated electrode arrays with increasing aspect ratios and manufacturing constraints are explored by Takahata et al. [6].A combined method of mechanical peckdrilling and reverse electrical discharge machining (reverseEDM) was used by Yu-Lung Hwang et al. [7] to fabricate a circular cross-section micro-pin array with high hardness and high density in a fast and efficient way. Mujumdar et al. [8] fabricated a micro-rod with a diameter of $60 \mathrm{~mm}$ and a highaspect-ratio of 33 using the R-MEDM process. Their analysis of variance studies showed that the statistically significant factors that influence the response variables are the gap voltage and capacitance. Mastud et al. [9] did a comparative analysis of the process mechanics of micro-EDM and RMEDM, based on the voltage and current signals captured by high-speed powerscope. R-MEDM was found to be more stable (higher normal operation time) than the micro-EDM process under identical processing conditions. Due to its stable characteristics, R-MEDM can be robustly operated at capacitance $(100 \mathrm{nF})$ and voltage $(120 \mathrm{~V})$. R-MEDM results in structures having a higher surface roughness as compared to the surfaces obtained using MEDM [9]. Majumdar et al. [8] also observed that debris was deposited on the formed micropillars by the process of R-MEDM. This debris accumulation can be minimized by various methods. In this present study, 
the debris formations on micro-pillars were cleaned by using polishing slurry of alumina powder and titanium alloy etchant.

The objective of this paper is to form the micro-pillars on coarse grain Ti6Al4V material. Initially the grain size of the material was increased by using a heat treatment process. Gil et al. [10] proposed that the grain size increases when the heat treatment temperature and heat treatment time increase. In his work, the initial average grain size of the alloy was $54 \mu \mathrm{m}$. He observed that the average grain size after 120 minutes of heat treatment increased to $66 \mu \mathrm{m}$ at $700^{\circ} \mathrm{C}, 93 \mu \mathrm{m}$ at $750^{\circ} \mathrm{C}$ and $172 \mu \mathrm{m}$ at $800^{\circ} \mathrm{C}$. The final grain size was measured to be 358 $\mu \mathrm{m}$ after heating at $1000^{\circ} \mathrm{C}$ and of $429 \mu \mathrm{m}$ at $1100^{\circ} \mathrm{C}$ [10].The large grains would provide an opportunity to grow the micro-pillars on each grain, thus having single crystal micro-pillars. This gains special importance since single crystals are extremely important in many technologies like semiconductors, polarizer, infrared detectors, ultrasonic amplifiers, solid state lasers, piezoelectric, crystalline thin films for microelectronics and computer industries [11].

In this paper, Section 2 deals with the details of the experimental study. This is followed by section 3 that presents the results from the experimental study. Finally, conclusions are drawn from the study in section 4 .

\section{EXPERIMENTAL DETAILS}

The main objective of this work is to develop the micropillars on single crystal Ti6Al4V material. Also to find the effect of processing parameters, namely voltage, capacitance and threshold of spark circuit on the formation of micropillars.

The chemical composition of as received material is given in Table 1.

\section{A. A. Heat Treatment}

Alloys are in general heat treated-

- To minimise the internal residual stresses generated during fabrication (stress relieving).

- To produce an optimum combination of ductility, machinability, and dimensional and structural stability (annealing).

- To increase strength (solution treating and aging).

- To optimize special properties such as fracture toughness, fatigue strength, and high-temperature creep strength [12].

In this work; however, heat treatment was performed to increase the grain size. The main driving force ingrain growth results from the decrease in free energy, which is due to reduction of grain boundary area. Grain Growth takes place by diffusion, when the temperature is high and time is long. The grain growth is basically a decrease in the number of grains per unit volume or decrease in grain boundary area per unit volume or stored energy per unit volume.

TABLE I: CHEMICAL COMPOSITION OF TI6AL4V
\begin{tabular}{|c|c|}
\hline Elements & Percentage $(w t \%)$ \\
\hline $\mathrm{Al}$ & 5.8 \\
\hline $\mathrm{V}$ & 3.87 \\
\hline $\mathrm{C}$ & 0.057 \\
\hline $\mathrm{Mn}$ & 0.014 \\
\hline $\mathrm{Ni}$ & 0.004 \\
\hline $\mathrm{Mo}$ & 0.014 \\
\hline $\mathrm{Fe}$ & 0.018 \\
\hline $\mathrm{Ti}$ & Balance \\
\hline
\end{tabular}

\section{B. Experimental setup and procedure}

Micropillar formation experiments were performed on a MikrotoolsTM high precision three axis micromachining centre. The machine had a resolution of $0.1 \mu \mathrm{m}$ and $\pm 1 \mu \mathrm{m}$ accuracy. A biocompatible grade of Ti alloy (Ti6Al4V) was selected as the anode and a copper foil of $100 \mu \mathrm{m}$ thickness was used as the cathode. Figure 1 shows the overall schematic of the experimental setup of R-MEDM. Figure 2 shows the enlarged view of anode cathode interface of actual setup. Holes in the $100 \mu \mathrm{m}$ thick copper foil (anode) were machined using laser machining. EDM oil was used as the dielectric medium during R-MEDM machining. A face turned and polished Ti6Al4V rod of $1.5 \mathrm{~mm}$ in diameter was mounted on the $\mathrm{Z}$-axis of the machine while the thin copper foil was mechanically fastened on machine table. A function generator was used to generate an electrical signal of a suitable frequency which was further amplified using an $\mathrm{AE}$ Techtron Liner amplifier. Tektronix high speed digital powerscope-TPS 2014, $100 \mathrm{MHz}, 1 \mathrm{GS} / \mathrm{sec}$ along with A622 current probe were used to capture the voltage and current signals.

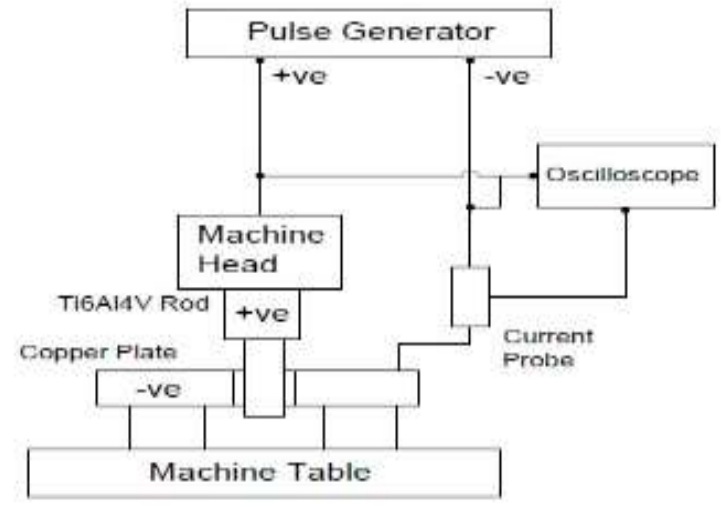

Fig. 1. Schematic of experimental setup for R-MEDM



Fig. 2. Enlarged view of anode-cathode interface of actual setup 

[13]:

The process parameters used in this study are as follows

Voltage and capacitance: In RC pulsed circuit, pulse energy $(\mathrm{E})$ varies squarely with voltage $(\mathrm{V})$ and linearly with a capacitance $(\mathrm{C})$, given by equation (1)

$$
E=\frac{1}{2} \mathrm{CV}^{2}
$$

Pulse energy affects the size, shape and distribution of craters formed on anode surface. Therefore, it is believed that both these parameters will affect the response of R-MEDM [13]. The surface roughness of EDM-machined surfaces is also affected by the energy per spark [14].

Threshold: Threshold is another important electrical parameter which controls the machining stability of $\mathrm{R}$ MEDM. Threshold mainly controls the sensitivity of the RMEDM process towards arcing. The process is more sensitive to arcing at low threshold values [13].

Table 2 summarizes the experimental conditions used in this study. The voltage, capacitance and threshold of the spark circuit were the three system parameters that were varied for the R-MEDM experiments.

TABLE II: EXPERIMENTAL CONDITIONS

\begin{tabular}{|c|c|c|c|c|c|}
\hline \multirow{2}{*}{\multicolumn{6}{|c|}{$\begin{array}{l}\text { Anode: Electrolytic copper plate of } 100 \mu \mathrm{m} \mathrm{t} \\
\text { of } 70 \mu \mathrm{m}, 80 \mu \mathrm{m}, 100 \mu \mathrm{m} \text { and } 150 \mu \mathrm{m} . \\
\text { Cathode: Ti6Al4V rod of } \phi 1.5 \mathrm{~mm} \text {. } \\
\text { Processing Conditions }\end{array}$}} \\
\hline & & & & & \\
\hline Expt. & 1 & 2 & 3 & 4 & 5 \\
\hline Voltage (V) & 80 & 90 & 90 & 95 & 105 \\
\hline $\begin{array}{c}\text { Capacitance } \\
(\mu \mathrm{F})\end{array}$ & 0.01 & 1 & 0.1 & 0.1 & 0.1 \\
\hline $\begin{array}{l}\text { Threshold of } \\
\text { spark circuit } \\
(\%)\end{array}$ & 40 & 40 & 60 & 40 & 50 \\
\hline $\begin{array}{c}\text { Machining time } \\
\text { (minutes) }\end{array}$ & 325 & 130 & 170 & 210 & 150 \\
\hline Dielectric fluid & & & $\mathrm{M}$ & & \\
\hline
\end{tabular}

\section{Debris Deposition}

For R-MEDM process, normally the debris is deposited between the electrodes and machined micro pin. One of the probable reasons for this is that, for a higher short circuit time percent, current passes continuously through the workpiece for longer duration. This results in localized heating by depositing the debris on the micro-pillar as shown in figure 3 . Debris particle drastically reduces the strength of dielectric [15].

For this purpose, polishing slurry was made so that the debris can be removed from the surface of micropillars. Polishing slurry was made by using alumina powder and the etchant (which can etch titanium alloy). Alumina powder is used due to its use in polishing. The main types of polishing alumina are calcined and polycrystalline abrasives. Calcined powders include fused, platey or levigated (air classified/sized) alumina. As the polycrystalline abrasives are used for polishing hard metal samples, it was used in this study for micropillars polishing. The size of the micropillars is in micron so direct polishing mechanism cannot be used. For that reason, mechanism of polishing slurry was made to clean the micropillars.

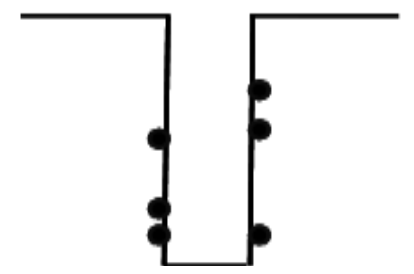

Fig. 3. Debris deposition to micro-pin surface [9]

Chemical composition of the etchant is shown in table 3

TABLE III: CHEMICAL COMPOSITION OF ETCHANT

\begin{tabular}{|l|l|}
\hline $\mathrm{HNO}_{3}$ & $5 \mathrm{ml}$ \\
\hline $\mathrm{HF}$ & $10 \mathrm{ml}$ \\
\hline Distilled water & $92 \mathrm{ml}$ \\
\hline
\end{tabular}

Care should be taken to ensure that Hydrofluoric acid and Nitric acid is added after addition of water

\section{III.RESULTS AND DISCUSSION}

\section{A. Grain Growth}

Microstructure has a very significant effect on the mechanical properties of Ti6Al4V [16]. The grain size of the received sample is $1.9 \mu \mathrm{m}$. With the goal to increase the grain size, heat treatment was performed at $825^{\circ} \mathrm{C}$, (well below beta transus temperature) and held up for a period of $4 \mathrm{hr}$ to have grain growth followed by air cooling to room temperature. Figure 4 shows the EBSD (electron backscatter diffraction) images of the microstructures of (a) as received sample and (b) effect of heat treatment at $825^{\circ} \mathrm{C}, 4 \mathrm{hr}$, A.C. The grain size observed from this heat treatment was $4.9 \mu \mathrm{m}$. A second heat treatment was carried at $825^{\circ} \mathrm{C}$ for $6 \mathrm{hr}$, A.C. and grain size of $7.1 \mu \mathrm{m}$ was observed. From the above heat treatment processes, it was observed that the grain size was increasing, but not up to the desired level.

After various heat treatment procedures, the required grain size was obtained at $1050^{\circ} \mathrm{C}, 4 \mathrm{hr}$, A.C. Figure 5 shows the optical image of the microstructure of the received sample while figure 7 shows the optical image of heat treatment at $1050^{\circ} \mathrm{C}$, $4 \mathrm{hr}$ then A.C respectively.

\section{B. Effects of process parameter}

The first micropillar experiment resulted in a bended pillar as shown in the figure 6 (Experiment 1). This could be because the selected processing parameters were not suitable for Ti6Al4V material. Another possible reason for this type of behaviour may be that there was a slight movement of the copper plate which was used during the experiment by RMEDM. 



Fig. 4. EBSD images of the Microstructure of a) as received, b) Heat treatment at $825^{\circ} \mathrm{C}, 4 \mathrm{hr}$, A.C.
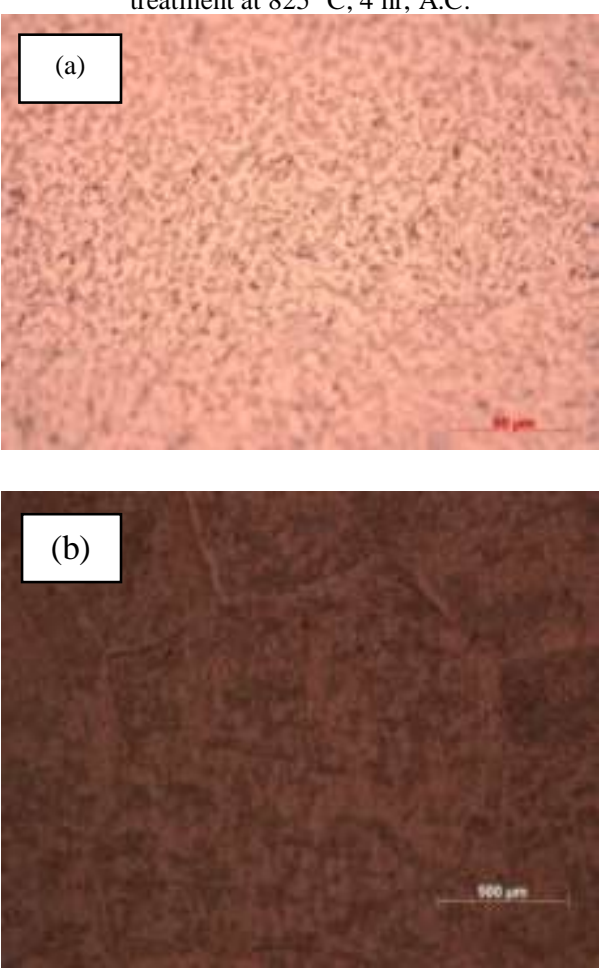

Fig. 5. SEM images of the Microstructure of a) as received, b) Heat treatment at $1050^{\circ} \mathrm{C}, 4 \mathrm{hr}$, A.C.

In the second experiment (Fig 6 Experiment no. 2), the micropillar growth was restricted to a certain length. As compared to the previous experiment, in which the micropillar bends, the value of capacitance was increased in this experiment. However, it was later realized that the increased in capacitance was more than the desired value. Due to this the micro-hole of the copper plate got eroded after 130 minutes of machining.
The optimized capacitance was used to produce the next micro-pillar (Experiment no. 3). This experiment showed that a large amount of debris was formed in the primary zone, i.e.at the root of the micropillar. An increased material erosion rate for the R-MEDM would imply the generation of a large volume of debris in the primary zone [9]. Here, the threshold was identified as the main influencing factor for the debris formation. A debris free region is observed from the midpoint to the end of the tip. In that region, the micropillar has a relatively clean surface with the aspect ratio of around 4 . Below the midpoint, the micropillar was seen to have an increasing width. The overall aspect ratio of the micropillar was around 8.

The threshold of the process were altered (based on the understanding from experiment no. 3) for the next experiment (experiment no. 4). The experiment no. 4 was found to have no debris formation; however, the dimensional accuracy of the micropillar was very poor. The copper plate contained a micro-hole of $150 \mu \mathrm{m}$ diameter; however, the diameter of the produced micropillars in this experiment was only $85 \mu \mathrm{m}$ at the tip (an error of $43 \%$ for a micropillar of $150 \mu \mathrm{m}$ ).

Moving along the length of the rod from root to tip, the absolute value of the percentage error changes. The percentage error is least at the root of the pillar. The large error was thought to be due to insufficient gap voltage (which was kept at 90V). Hence, in the next experiment (experiment 5), the micropillar was made using a gap voltage of $105 \mathrm{~V}$. In this experiment the percentage error was found to be very small. This implies that a gap voltage of $105 \mathrm{~V}$ is closer to optimal than $90 \mathrm{~V}$. At the low gap voltage, the gap between the electrode and the Workpiece is very small, which hinders the process of debris removal. Also, the erosion energy is not sufficient enough to remove the debris formed around the holes. This results in the accumulation of debris particles at the tool-workpiece interface resulting in frequent shortcircuiting and the consequent workpiece retraction. Due to lift-off of the spindle head after arcing, the tip of the electrode was subjected to sparks on numerous occasions and consequently the error is higher at the tip due to higher material erosion. Experiment at an intermediate gap voltage of $95 \mathrm{~V}$ was also conducted. For the $95 \mathrm{~V}$ case, the processing time was $210 \mathrm{~min}$, whereas for the $105 \mathrm{~V}$ case the processing time was shorter $(150 \mathrm{~min})$. This indicated that at $95 \mathrm{~V}$, the tip was exposed to more sparks, which resulted in higher material erosion and therefore the increased percentage error. However, for the $105 \mathrm{~V}$ case, the erosion energy was sufficiently high and hence the machining time was low, consequently the exposure of the tip was reduced, thereby imparting greater accuracy. Better accuracy at $105 \mathrm{~V}$ is also supported by literature, where it has been reported that at higher voltages ( $100 \mathrm{~V}$ or higher), the energy of the sparks is sufficiently high to remove debris particles. 


\section{Experiment 1}



Experiment 2

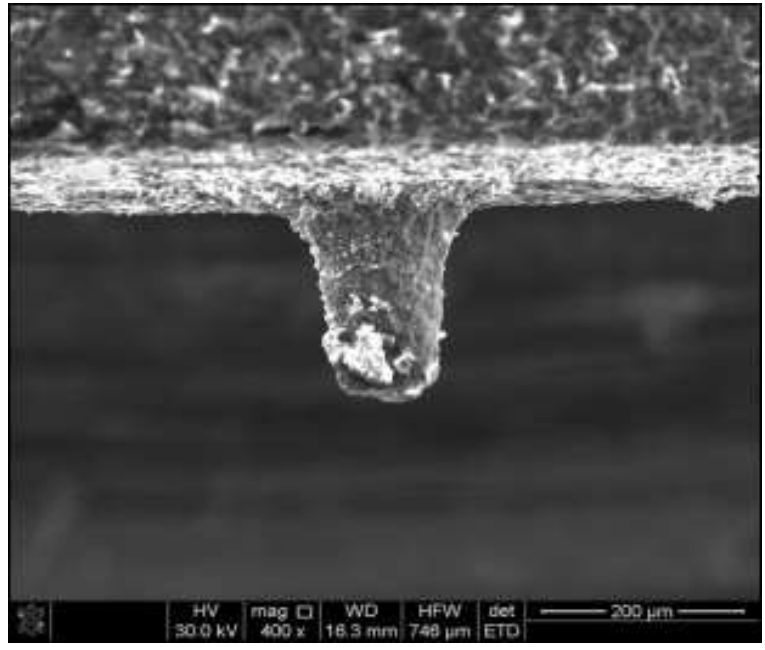

\section{Experiment 3}



\section{Experiment 4}

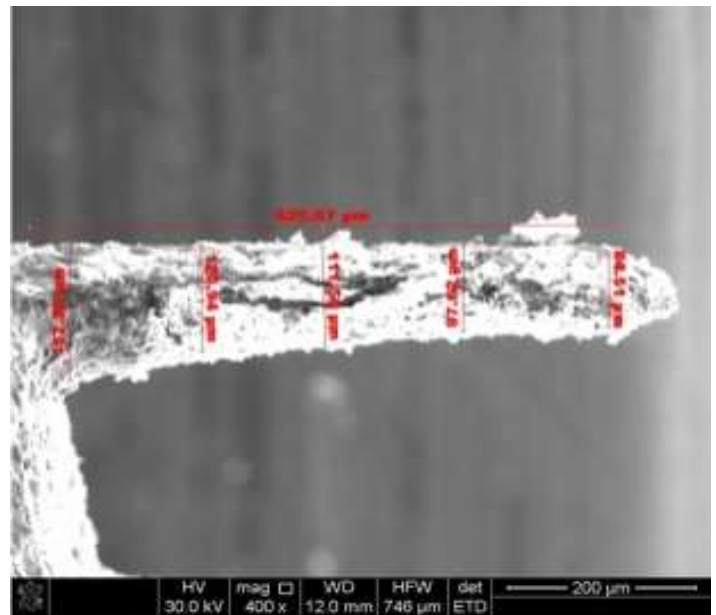

\section{Experiment 5}

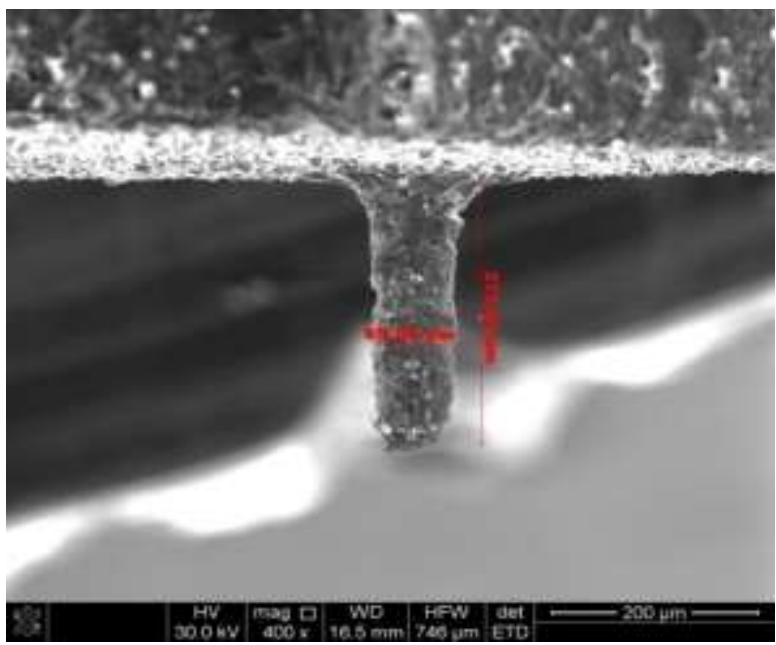

Fig. 6. Typical images of fabricated micropillars

In the earlier experiments (experiments no. 1 and 2), the capacitance used was $0.01 \mu \mathrm{F}$ and $1 \mu \mathrm{F}$ respectively. For experiment no. 5, the capacitance used was $0.1 \mu \mathrm{F}$. As the material is of titanium alloy (difficult to machine), the capacitance value needs to be large. But at a value of $1 \mu \mathrm{F}$, the copper plate gets eroded (experiment no. 2). So the moderate value of capacitance of $0.1 \mu \mathrm{F}$ was chosen for later experiments. Another important electrical parameter is the threshold, which controls the machining stability of RMEDM. Larger threshold implies more number of chargingdischarging cycles of the capacitor. In the experiment 3, threshold value was at $60 \%$. Due to the large threshold value, large amount of debris was formed in the primary zone, i.e.at the root of the micropillar. Due to this intermediate experiments (not reported in this work) at threshold value of $40 \%$ and $50 \%$ were performed. At a $40 \%$ value, machining time was very large. Thus, an optimal threshold value of $50 \%$ was selected. Also, the dimensional accuracy was observed to be better at the threshold value of $50 \%$ than at $40 \%$. Hence all the later experiments were performed at a threshold value of 50\% (Experiment 4 and 5). 


\section{Polishing slurry}

The surfaces of the micropillars were seen to have debri formed on it. For this reason, the polishing slurry mechanism was used to clean the surface of the micropillars. Polishing slurry contained alumina powder and titanium alloy etchant. The surface of the micropillars before and after polishing slurry is shown given in figure 7 . Figure 7 (a) shows large amount of debri formed on the surface of micropillar. Both the alumina powder and the etchant were mixed in a beaker. A mechanism was prepared to stir the slurry while the micro pillars are immersed in it. It was then polished for 25-30 min. After the polishing of micropillars, Scanning electron microscopy image of that micropillar was taken (fig. 7 (b)). Figure 7 (b) shows that the debris formed on the surface of micropillars was removed by large amount. The surface now appears much cleaner than the previous one. This was due to the polishing slurry of alumina powder and etchant.
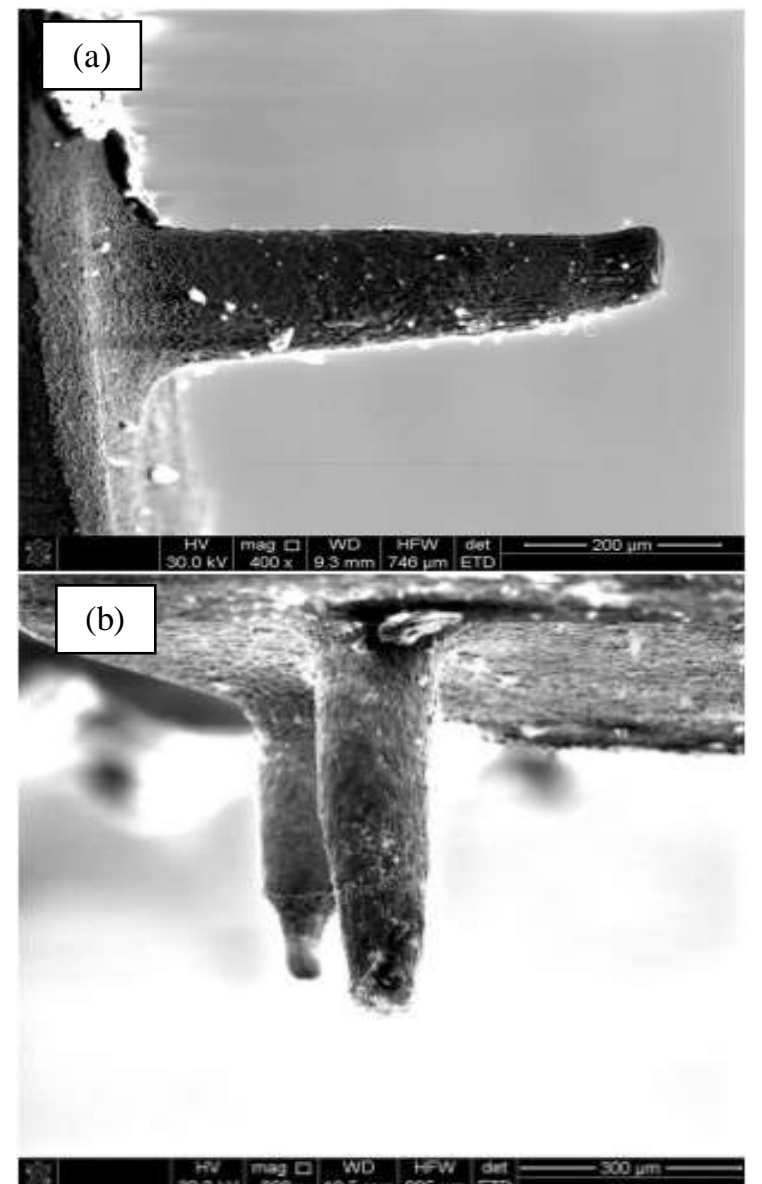

Fig. 7. Surface of the micropillars (a) before polishing and (b) after polishing.

\section{IV.CONCLUSSION}

Titanium alloy Ti6Al4V was used to produce micro-pillars using reverse micro electro discharge machining (R-MEDM). Heat treatment, at a temperature of $1050^{\circ} \mathrm{C}$ for $4 \mathrm{hr}$ holding time, followed by air cooling, was performed to increase the grain size of the alloy. This was done so that each micro-pillar would be formed on separate grain leading to single crystal micro pillars. Optical microscopy was used to see the grain morphology, SEM was used for higher resolution and EBSD was used to study the texture.
A rough and pitted surface was observed at the root of the micro-pillars so produced by R-MEDM process. The generation of larger craters at high voltage and capacitance resulted in higher surface roughness on the micro-pillars. Dimensional errors at the tip of micro-pillars are always greater than those at the root. At large values of capacitance $(1 \mu \mathrm{F})$, micro-hole of copper plate got eroded. While at large value of threshold, large amount of debri was formed at the root of the micropillars. A polishing slurry mechanism was used to remove the debri and improve the surface finish of the micropillars. The $\mathrm{R}$ - MEDM process is found to give the best results for the heat treated $\mathrm{Ti} 6 \mathrm{Al} 4 \mathrm{~V}$ alloys at a gap voltage of $105 \mathrm{~V}$, capacitance of $0.1 \mu \mathrm{F}$ and a threshold of $50 \%$.

\section{ACKNOWLEDGEMENT}

The authors gratefully acknowledge the support provided for this work by National Centre for Aerospace Innovation and Research, IIT-Bombay, a Dept. of Science and Technology-Government of India, The Boeing Company and IIT Bombay Collaboration. They would also like to thank Mr. Pranay Radke for his help in heat treatment optimization.

\section{REFERENCES}

[1] C. Leyens and M. Peters, "Titanium and Titanium alloys", pp. 333-350, (2003) http://dx.doi.org/10.1002/3527602119

[2] Satendra Kumara, T.S.N. Sankara Narayanana, S. Ganesh Sundara Ramanb, S.K. Seshadrib, "Thermal oxidation of Ti6Al4V alloy: microstructural and electrochemical characterization", material chemistry and physics vol.119, pp. 337-346, (2010).

[3] Chamran, F., Yeh, Y., Min, H.S., Dunn, B. and Kim, C.J. "Fabrication of high-aspect-ratio electrode arrays for three-dimensional microbatteries", Journal of Micromechnical Systems, Vol. 16, No. 4, pp.844853, (2007).

http://dx.doi.org/10.1109/JMEMS.2007.901638

[4] Weng, F.T. and Her, M.G. "Study of the batch production of micro parts using the EDM process", International Journal of Advanced Manufacturing Technology, Vol. 19, No. 4, pp.266-270, (2007). http://dx.doi.org/10.1007/s001700200033

[5] Kim, H., Park, B. J., and Chu, C. N, "Fabrication of multiple electrodes by reverse EDM and their application in micro-ECM" J. Micromech. Microengng, 16, pp. 843-850, (2006). http://dx.doi.org/10.1088/0960-1317/16/4/022

[6] Ken'ichi Takahata And Yogesh B. Gianchandani, "Batch mode microelectro-discharge machining", Journal of micro electro-mechanical systems, vol. 11, no. 2, april (2002).

[7] Yu-Lung Hwang, Chia-Lung Kuo, Shun-Fa Hwang, "Fabrication of a micro-pin array with high density and high hardness by combining mechanical peck-drilling and reverse-EDM", Journal of Materials Processing Technology, 210, pp. 1103-1130, (2010) http://dx.doi.org/10.1016/j.jmatprotec.2010.02.022

[8] Mujumdar, S., Mastud, S., Singh, R.K. and Joshi, S.S. "Experimental characterization of reverse micro-electrical discharge machining process for machining of high aspect ratio microrod array", ImechE Journal of Engineering Manufacture: Part-B, Vol. 224, No. 5, pp.778-794, (2009).

[9] Sachin Mastud, Ramesh K. Singh, Johnson Samuel, Suhas S. Joshi, "Comparative analysis of the process mechanics in micro-electrical discharge machining (EDM) and reverse micro-edm", Proceedings of the ASME 2011 International Manufacturing Science and Engineering Conference MSEC 2011 June 13-17, (2011), Corvallis, Oregon, USA. http://dx.doi.org/10.1115/MSEC2011-50122

[10] Gil F.X., Rodriguez D., Plancll J.A., "Grain Growth Kinetics of pure titanium”, Scripta Metallurgica of Materialia, Vol 33(8), pp. 13611366 http://dx.doi.org/10.1016/0956-716X(95)00367-5

[11] William D. Callister, Jr., "Material science and engineering”, seventh edition, John Wiley \& Sons, Inc.

[12] Titanium: A Technical Guide, 2nd Edition, 2000 ASM International. 
[13] Mastud, S., Singh R.K. and Joshi, S.S., 2010 "Analysis of fabrication of arrayed microrods on Tungsten Carbide using reverse micro-EDM", Int. J. Manufacturing technology and Management, Vol. 26, Nos. 1/2/3/4, (2012).

[14] Krishna Kiran, M. P. S. and Joshi, S. S., "Modeling of surface roughness and the role of debris in micro-EDM." Trans. ASME, J. Mfg Sci. Engng, 129, pp. 265-273, (2007)

[15] Kunieda, M., Lauwers, B., Rajurkar, K.P., and Schumacher, B.M., "Advancing EDM through Fundamental Insight Into Process", CIRP Annals, Manufacturing Technology, 54, pp. 64-87, (2005). http://dx.doi.org/10.1016/S0007-8506(07)60020-1

[16] L. Zeng, T.R. Bieler, "Effects of working, heat treatment, and aging on microstructural evolution and crystallographic texture of $\alpha, \alpha^{\prime}, \alpha^{\prime \prime}$ and $\beta$ phases in Ti-6Al-4V wire" Materials Science and Engineering A 392, pp. 403-414, (2005). http://dx.doi.org/10.1016/j.msea.2004.09.072



Mr. Rakesh V. Chaudhari: Gandhinagar, Gujarat, India.

Mr. Rakesh Chaudharil has completed his B. E. degree in Mechanical Engineering from Government College of Engineering Jalgaon, Maharashtra, India in 2012. He did his M.Tech. in Mechanical Engineering from SVNIT, Surat, India in 2014. As a part of dissertation, he had worked at Indian Institute of Technology, Bombay under National Centre for Aerospace Innovation and Research. He is currently pursuing Ph.D. from Pandit Deendayal Petroleum University (PDPU), Gandhinagar, India.

Presently he is working as a lecturer in School of Technology, Pandit Deendayal Petroleum University since July 2014.

Mr. Ashish Saxena: Mumbai, Maharashtra India.

Mr. Ashish Saxena has completed his M.Tech in Material Science and Engineering from National Institute of technology Tiruchirappalli, India in 2000. He is currently pursuing his $\mathrm{PhD}$ from Indian Institute of technology Bombay, Mumbai, India. His research area is Materials deformation and micro structural characterization.

Dr. Asim Tewari: Mumbai, Maharashtra, India

Dr. Asim Tewari is Professor In-Charge of NCAIR (www.ncair.in) and faculty in the Department of Mechanical Engineering at India Institute of Technology Bombay and incharge of National Centre for Aerospace Innovation and Research (NCAIR). Prior to this he was a staff researcher at General Motors Global R\&D center in Bangalore. He graduated with a B.Tech degree from IIT Kanpur, India followed by MS and PhD from Georgia Institute of Technology, Atlanta, USA. After his doctorate he was briefly with National Aerospace Laboratories. Subsequently, he joined IIT Kanpur where he served as assistant professor for over 3 years before joining General Motors Global R\&D center in Bangalore.

His area of research is in mathematical models for microstructural-mechanics. He has extensively published in peer reviewed journal and has been awarded many international patents. His pioneering work in 3D microscopy has been widely cited including reproduction in ASM handbooks. He is in the editorial board of several international Journals including Metallurgical and Materials Transactions and Image Analysis \& Stereology. He is also a reviewer for several international journals with prominent ones being Proceedings of Royal Society of London and Acta Materialia, He has served as advisory committee member for various national \& international research boards and conferences. He has won several awards and recognitions for his research and teaching with the prominent ones being, Excellence in Teaching award, IIT Bombay, Cambell Award for excellence in Science General Motors, and membership of International materials honor society Alpha Sigma Mu. 